Araştırma Makalesi/Research Article

\title{
Merlot ve Cabernet Sauvignon Üzüm Çeşitlerinde (Vitis vinifera L.) Çiçek Salkımı Çiçek Organ Taslaklarının Morfolojik Gelişim Safhalarının Belirlenmesi
}

\author{
Zeliha Gökbayrak* \\ Hakan Engin \\ Çanakkale Onsekiz Mart Üniversitesi Ziraat Fakültesi, Bahçe Bitkileri Bölümü, 17020, Çanakkale, Türkiye \\ *Sorumlu yazar: zgokbayrak@comu.edu.tr
}

Geliş Tarihi: 09.10.2018

Kabul Tarihi: 04.02.2019

\section{$\ddot{O} \mathbf{z}$}

$\mathrm{Bu}$ araştırma asma çiçek salkımı ile çiçek organ taslaklarının gösterdiği morfolojik değişimlerin gelişim dönemleri ile birlikte ortaya konulması amacıyla yürütülmüştür. 'Merlot' ve 'Cabernet Sauvignon' (Vitis vinifera L.) üzüm çeşitlerinin çiçek organ taslaklarının oluşumu ve gelişimi mikroskop altında incelenmiştir. Tomurcuk örnekleri, 2016 yılı Mart ayı başından başlayarak 5-10'ar gün arayla alınarak Mayıs ayı ortasına kadar FAA solüsyonu içinde muhafaza edilmiştir. Çiçek salkımı taslağının belirginleşmesinden sonra çiçek organ taslakları sırasıyla çanak yaprak, taç yaprak, erkek organ ve dişi organ olarak farklılaşmıştır. Günümüz literatür bilgisine ek olarak, özellikle eșey organlarının gelișimi aşamaları daha detaylandırılmıștır. Elde edilen görüntüler, taç yaprak taslağının tepe noktasında birleşip kaliptrayı oluşturmadan hemen öncesinde erkek organ taslağının gelişmeye başladığını ve erkek organ taslakları ile takip eden dişi organ taslağı gelişiminin ortalama 5 gün içerisinde hızlı bir kütlesel büyüme sonucunda tamamlandığını ortaya koymuştur. Çalışma, 'Merlot' ve 'Cabernet Sauvignon' çiçeklerinde, kış dinlenme dönemi içerisinde gözlerde generatif organ taslaklarının yapılanmasına yönelik bir gelişme olmadığını, çiçek organ taslaklarının farklılaşmasının sürmeyle birlikte Nisan ayında başladığını ve bütün çiçek organ taslaklarının yaklaşık üç haftalık kısa bir dönemde şekillendiğini ortaya koymuştur.

Anahtar Kelimeler: Vitis vinifera L., Çiçek Oluşumu, Çiçek Organ Taslağı.

\section{Determination of Morphological Development Stages of Inflorescence and Flower Organ Primordia in Merlot and Cabernet Sauvignon Grape (Vitis vinifera L.) Cultivars \\ Abstract}

This research aimed to determine development period of inflorescence with floral primordia of grapevine in association with growth period. Growth and development of inflorescence and flower primordia of 'Merlot' and 'Cabernet Sauvignon' grape cultivars (Vitis vinifera L.) were examined under microscopy. Bud samples were taken every 5 to 10 days starting from the beginning of March to mid-May in 2016 and they were preserved in FAA solution. After inflorescence primordium became clear, floral primordia differentiated in the order of sepals, petals, androecium, and gynoecium. In addition to the literature today, stages of sexual organ development were further detailed. Images obtained indicated that androecium primordia started to develop just before the calyptra emerged around the edges at the top and that development of both androecium and gynoecium primordia occurred within 5 days of each other with swift mass growth. This study showed that in the flowers of 'Merlot' and 'Cabernet Sauvignon', floral organ differentiation started to grow after budbreak in April and that all floral parts completed their differentiation and growth within short period of three weeks.

Keywords: Vitis vinifera L., flower formation, flower primordia.

\section{Giriş}

20. yüzyılın başlarında Synder (1933), Barnard ve Thomas (1933) ve Winkler ve Shemsettin (1937) tarafından asma sürgünlerinin ve üzerlerinde gelișen generatif organların morfolojisi incelenmiştir. $\mathrm{Bu}$ çalışmalar teknolojinin elverdiği ölçüde kış gözlerinin incelenmesi suretiyle yapılmıştır. Daha sonraki yıllarda May (1966), Alleweldt ve Balkema (1965), Carolus (1970), Pratt (1971), Scholefield ve Ward (1975), Srinivasan ve Mullins (1981), Staudt (1982), Morrison (1991) ve Ebadi (1996) tarafından çiçek oluşumu ve gelişimi hakkındaki bilgiler hem morfoloji hem de etkili faktörler açısından detaylandırılmıştır. Ülkemizde ise floral gelişme safhalarının belirlenmesine yönelik ilk çalışmalar Fidan (1966), Ağaoğlu (1969) ve Odabaş (1976) tarafından yapılmıştır.

Asmalarda çiçek oluşumu karmaşık ve uzun bir periyodu kapsamaktadır. Çiçek oluşumunun indüksiyon, başlama ve erken farklılaşmayı kapsayan ilk bölümü birinci sezon içinde gerçekleşmekte 
ve sürme ile birlikte farklılaşma ise ikinci sezonda olmaktadır. Çeşide ve çevresel koşullara bağlı olarak 1-3 adet çiçek salkımı primordiyumu oluştuktan sonra kışlık göz dinlenmeye girmektedir (Pratt 1971). Bazı araştırıcılar, yaz sonunda dinlenmeye girmeden önce sepal (kaliks) primordiyumlarının da çiçek salkımı primordiyumu içinde gözüktüğünü (Alleweldt ve Balkema 1965, Alleweldt 1966, Alleweldt ve İlter 1969, Ağaoğlu 1971) belirtirken Jones ve ark. (2009) ise kış gözünde mitoz bölünmenin devam ettiğini ve çiçek salkımı primordiyumunun kış dinlenmesi boyunca gelişmesini sürdürdüğünü göstermiştir.

Görüldüğü üzere literatürde asma floral gelişmesinin aşamaları hakkında farklı görüşler mevcuttur. $\mathrm{Bu}$ araştırma ile bölgemiz şartlarında Cabernet Sauvignon ve Merlot şaraplık üzüm çeşitlerinde çiçek ve çiçek organ taslaklarının farklılaşma aşamalarının daha ayrıntılı tespit edilmesi amaçlanmıştır.

\section{Materyal ve Yöntem}

Araştırmaya konu olan örnekler, Çanakkale ili Dardanos mevkiinde bulunan Çanakkale Onsekiz Mart Üniversitesi, Ziraat Fakültesi, Bahçe Bitkileri Bölümü'ne ait deneme ve araştırma parselinden temin edilmiştir. Araştırmada 'Merlot' ve 'Cabernet Sauvignon' (Vitis vinifera L.) şaraplık üzüm çeşitleri kullanılmıştır. Fransa orijinli bu çeşitlerin taneleri küçük, yuvarlak şekilli ve koyu mavi-siyah renklidir (Çelik, 2006). Çeşitler 5BB (Vitis berlandieri x V. riparia) üzerine aşılıdır. Araştırma, Çanakkale Onsekiz Mart Üniversitesi, Ziraat Fakültesi, Bahçe Bitkileri Bölümü’ne ait Fizyoloji ve Mikroskopi laboratuvar olanaklarından faydalanarak gerçekleştirilmiştir.

Örnekler (kış gözleri ve sürme ile gelişen taze sürgünler) 2016 yılında dinlenme dönemi sonundan (Mart ayı ortası) itibaren Eichorn ve Lorenz (1977)'a göre 1-15. fenolojik aşamalar arasında Mayıs ayının ortasına kadar toplanmıştır (Şekil 1). Örnek alımı her 5-10 günde bir yapılmıştır. Her bir alım döneminde örnek sayısı 10-20 arasında değişmiştir. Alınan örnekler 50-100 ml'lik şişelerde FAA çözeltisi (formalin \%10, alkol \%50 ve glasiyel asetik asit \%5) içerisinde en az 24 saat veya daha uzun süreyle muhafaza edilmiştir.

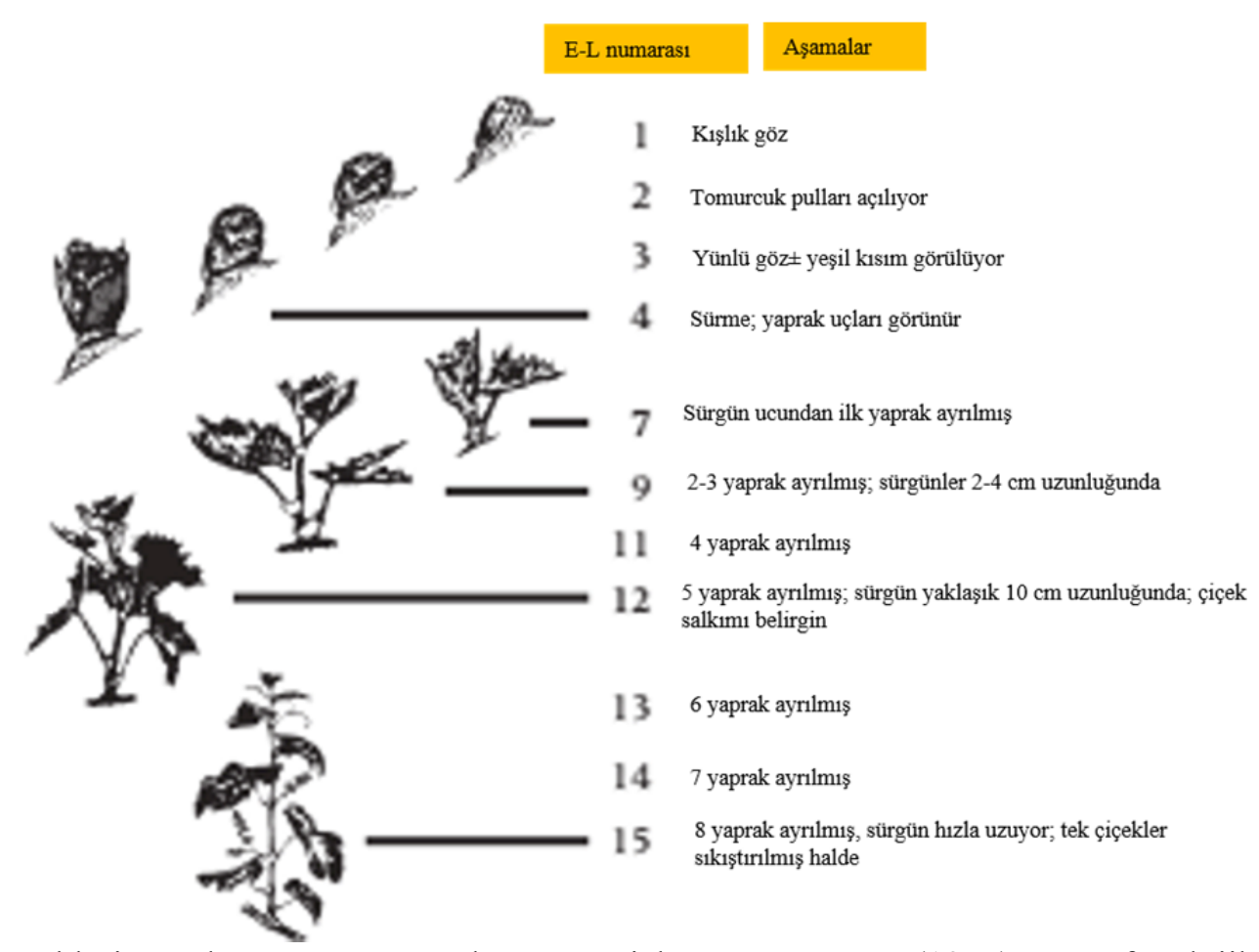

Şekil 1. Örneklerin toplanmasına esas oluşturan Eichorn ve Lorenz (1977) asma fenolojik gelişim aşamaları (1-15. aşamalar arasını göstermektedir).

Mikroskobik ölçüm ve görüntüleme yapılan örnekler, stereo mikroskop altında ok uçlu iğneler ve bisturi yardımıyla temizlenerek açılmıştır. Erkek ve dişi organ taslaklarının mikroskobik incelemesi için çanak yaprak taslakları ve taç yaprak taslakları ok uçlu iğneler yardımıyla kesilerek çıkarılmıştır. 
$\mathrm{Bu}$ işlemler, çiçek dokularından FAA'nın uzaklaşması esnasında meydana gelebilecek kurumaları önlemek için saf su içerisinde yapılmıştır. Yapılan incelemelerde floral gelişme safhalarının ifadesinde Srinivasan ve Mullins (1981) çalışmasından faydalanılmıştır.

Çiçek ve çiçek organ taslaklarının oluşumunun tespit edilmesinde Olympus SZX7 stereo mikroskop kullanılmıştır. Mikroskopa bağlı dijital mikroskop kamerası (Olympus LC20) ile örneklerin görüntülenmesi ve fotoğraflarının bilgisayara aktarılması sağlanmıştır. Örnekler üzerinde yapılan mikroskobik ölçümlerde LCmicro (Olympus Soft Imaging Solutions GmbH) yazılımı kullanılmıştır. Taslaklar üzerinde yapılan boyut ölçümleri alındığı zamana bağlı olarak ortalama değerleri ifade edecek şekilde görseller üzerine gösterilmiştir.

\section{Bulgular ve Tartışma}

Örneklerin alınmaya başladığı ilk fenolojik aşamalarda (E-L sistemi safha 1-2) kışlık gözlerin içinde çiçek salkımı taslaklarının gelişimi gözlenememiştir. İncelenen her iki asma çeşidinde çiçek organ taslaklarının farklılaşması gözler sürdükten sonra (E-L sistemi safha 3-5) meydana gelmiştir. Bu durum, gözlerde sürmeyle birlikte çiçek organlarının farklılaşıtığını ve geliştiğini belirten çalışmalarla (Breviglieri 1956, Fidan 1966, Pratt 1971) uyum göstermektedir. Ancak, kış dinlenme döneminde çanak yaprak halkasının da görülebildiğini ifade eden Alleweldt ve Balkema (1965), Alleweldt ve İlter (1969) ve Ağaoğlu (1971) ile çatışmaktadır.

Gözlerin sürmesini takip eden dönemde çiçek salkımları (Şekil 2) üzerindeki bireysel çiçekler (Şekil 3) şekillenmiş ve içinde çanak ve taç yaprak taslakları oluşmuştur (Şekil 4-5). Salkım üzerindeki çiçeklerde farklı çiçek organ taslaklarının oluşumu bir arada ancak farklı zamanlarda olmaktadır (Şekil 4, Boss ve ark. 2003). Tepe noktasında birleşen taç yaprak taslakları gelişimine devam ederken, çiçek taslağında çiçek sapı şekillenmektedir (Şekil 6). Çanak yaprak taslakların şekillenmesini takip eden aşamada taç yaprakların gelişmesi hızlı bir şekilde olmaktadır. Gelişmesine devam eden ve tepe noktasında birleşen taç yaprak taslakları, lopları oluşturduğunda çiçek taslağ tam şeklini almaktadır (Şekil 7).

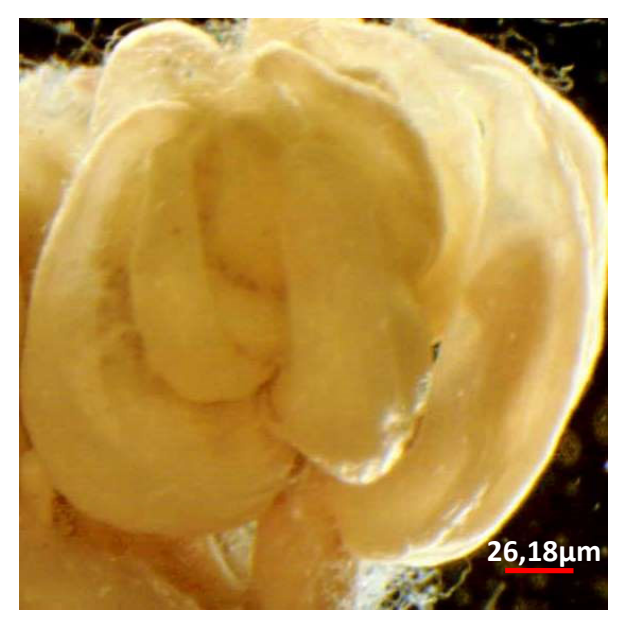

Şekil 2. 'Cabernet Sauvignon' çeşidinde çiçek salkımı dalcık taslağ (safha 8).

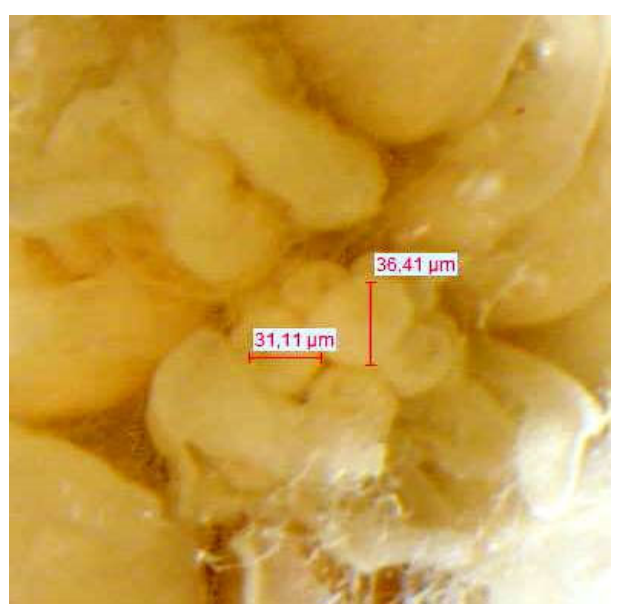

Şekil 3. 'Merlot' çeşidinde çiçek salkımı taslağında çiçek taslaklarının farklılaşması (safha 8). 


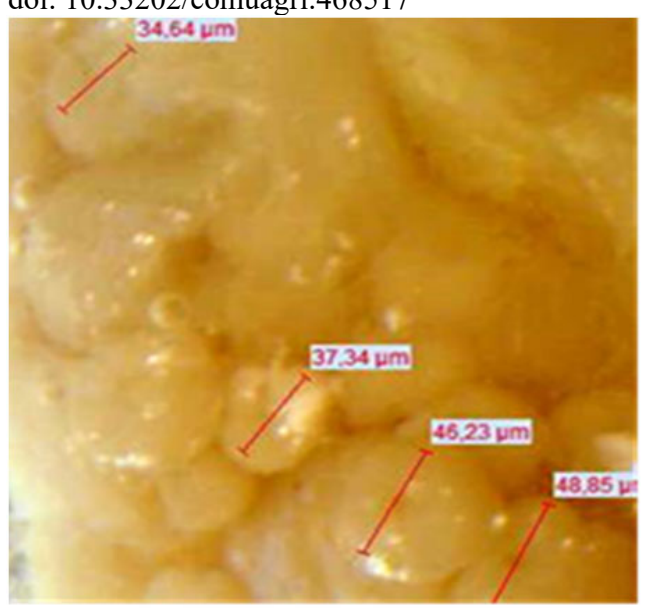

Şekil 4. Cabernet Sauvignon' çeşidinde salkım taslağ 1 üzerinde sıralanmış çiçek taslaklarında çanak yaprak taslağ 1 gelişimi (safha 9).

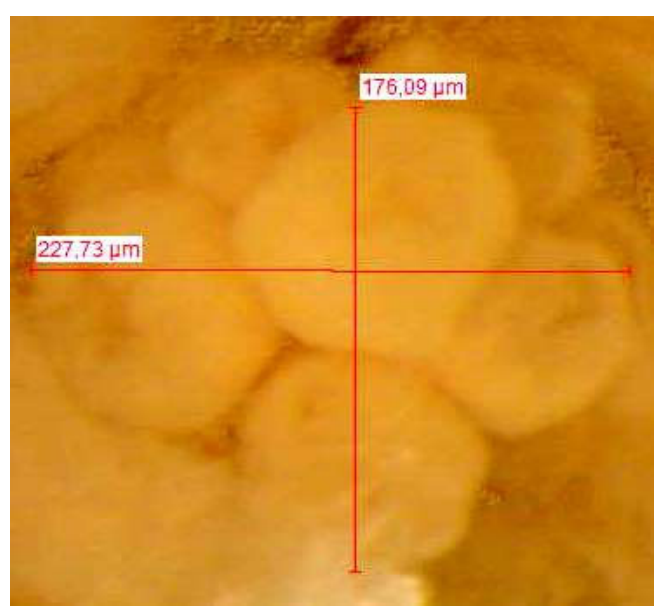

Şekil 5. 'Merlot' çeşidinde çiçeklerin üzerinde çanak ve taç yaprak taslakları (safha 9-10). Taç yaprakları üstten henüz birleşmemiş haldedir..

Srinivasan ve Mullins (1981) çiçek organ taslaklarının gelişimini, kaliptranın loblarının belirginleşmesi ve kapanması aşamasından (safha 10) sonra çiçeklenmeden hemen önceki çiçek safhası (no. 11) ile sonlandırmıştır. Oysa yapılan bu güncel çalışma taç yapraklarının gelişiminden sonra erkek organ taslaklarının ve dişi organ taslağının oluşumunu da ortaya koymaktadır. Yani gözlenen değişimler, Srinivasan ve Mullins'in (1981) çalışmasında belirtilen 10. ve 11. safhaların arasında meydana gelen değişimleri göstermektedir. Buna göre, taç yaprakların şekillenmesinden sonra erkek organların farklılaşması başlamaktadır (Şekil 8). Taç yaprakları kenarlardan birleşerek gelişmesini sürdürüp tepe noktasında birleşip kaliptrayı oluşturmadan önce erkek organ taslakları gelişmeye başlamaktadır. Erkek organda önce anter şekillenip gelişmesine rağmen filament gelişimi daha sonra çok hızlı bir şekilde gerçekleşmektedir. Hızlı bir gelişme gösteren erkek organ taslaklarında 5 gün içerisinde anter ve filament taslakları tam şekillerini almaktadır.

Erkek organ taslakların filamentin gelişmesinin hızlandığı aşamada dişi organın farklılaşması olmaktadır (Şekil 9). Bir tarafına baskı uygulanan dolu bir su balonu gibi asimetrik şekillenmeye başlayan dişi organ taslağının gelişimi hızlı olmaktadır (Şekil 7-9). İncelenen her iki çeşitte de 5 günlük sürede dişi organ taslağının yumurtalık, stil ve stigma kısımları şekillenmektedir (Şekil 10).

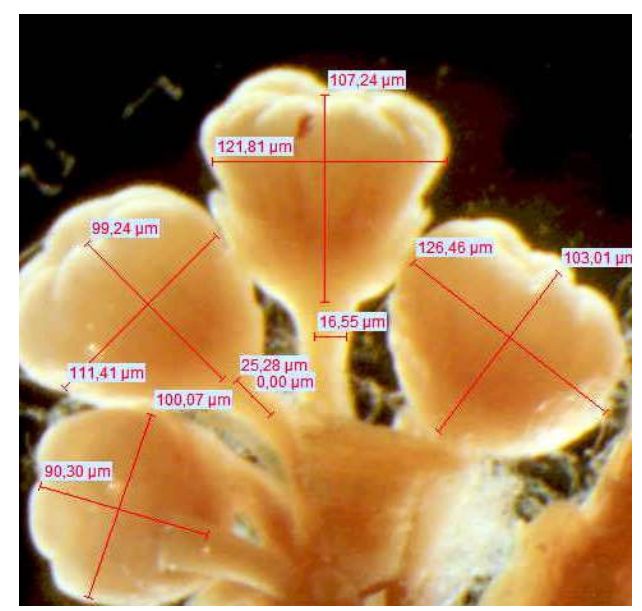

Şekil 6. 'Merlot' çeşidinde tepe noktasında birleșen taç yaprak taslakları ve çiçek taslağında sap şekillenmesi.

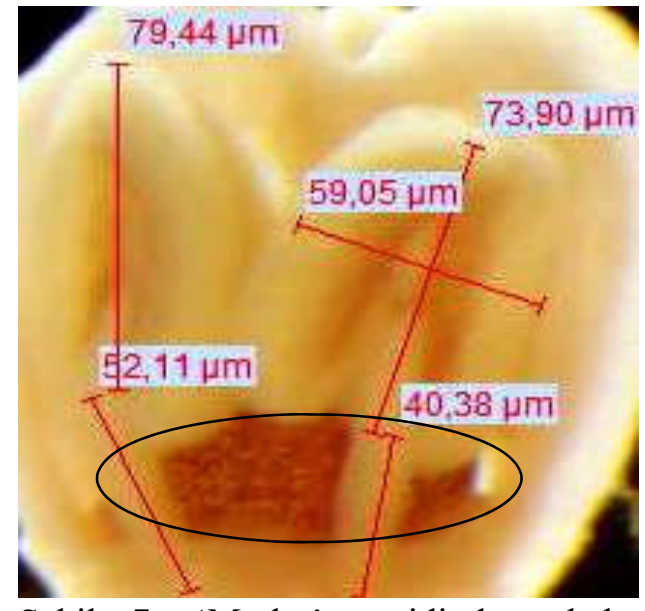

Şekil 7. 'Merlot' çeşidinde erkek organ taslaklarının şekillenmesi, dişi organ bir hücre yı̆̆ını şeklinde orta kısımda oluşmaya başlamış. 

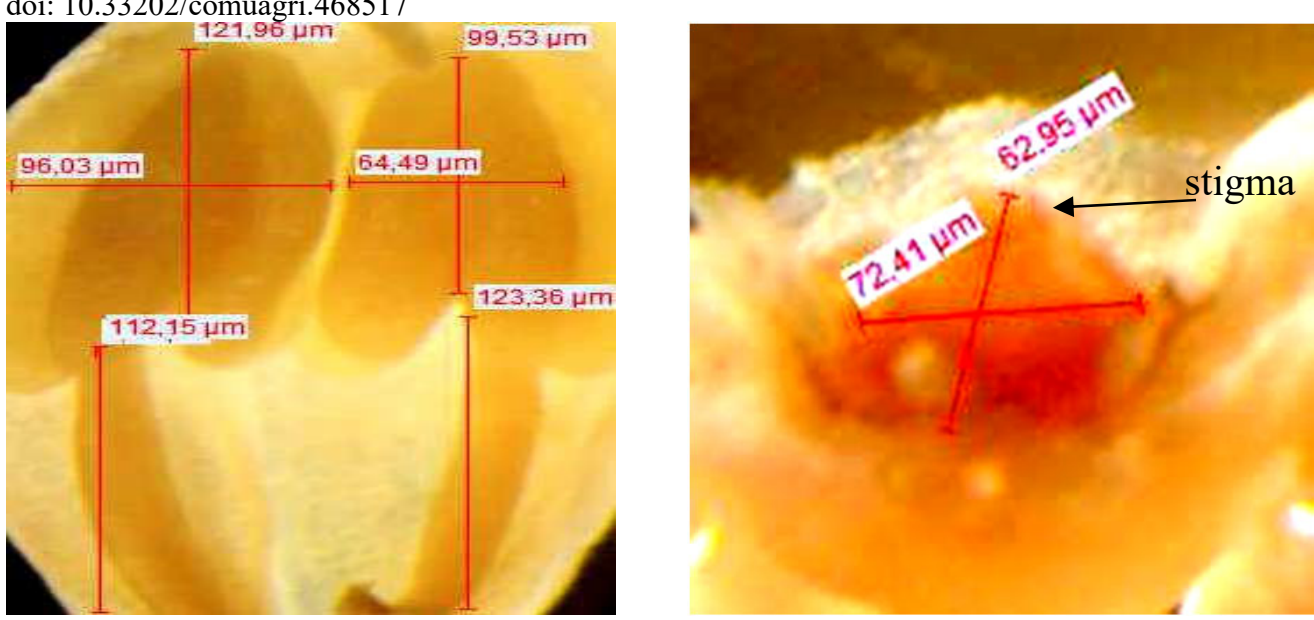

Şekil 8. 'Merlot' çeşidinde tam şeklini almış erkek organ taslakları. Görünüm amaçlı olarak dişi organ taslağ 1 çıkarılmıştır.

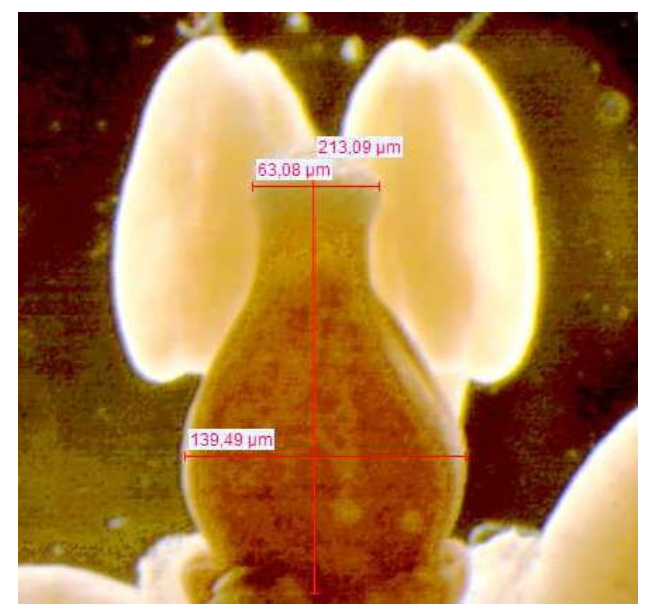

Şekil 10. 'Cabernet Sauvignon' çeşidinde tam şeklini almış dişi organ taslağ 1 (safha 11).

'Merlot' ve 'Cabernet Sauvignon' (Vitis vinifera L.) üzüm çeşitlerinin 2016 y1lı içinde çiçek ve çiçek organ taslaklarının farklılaşma safhaları ve zamanları şekil 11'de verilmiştir. Çiçek ve çiçek organlarının farklılaşması Nisan ayında gözler sürdükten sonra meydana gelmiştir. Bütün çiçek organ taslakları yaklaşık üç haftalık kısa bir periyotta şekillenmiştir. Çiçek organ taslakları sırasıyla çanak yaprak taslakları, taç yaprak taslakları, erkek organ taslakları ve dişi organ taslağı şeklinde farklılaşmıştır. Çiçek ve çiçek organ taslakları tam şeklini aldığı zaman (safha 11), çiçeklenmenin 1015 gün öncesine denk gelmiştir. 


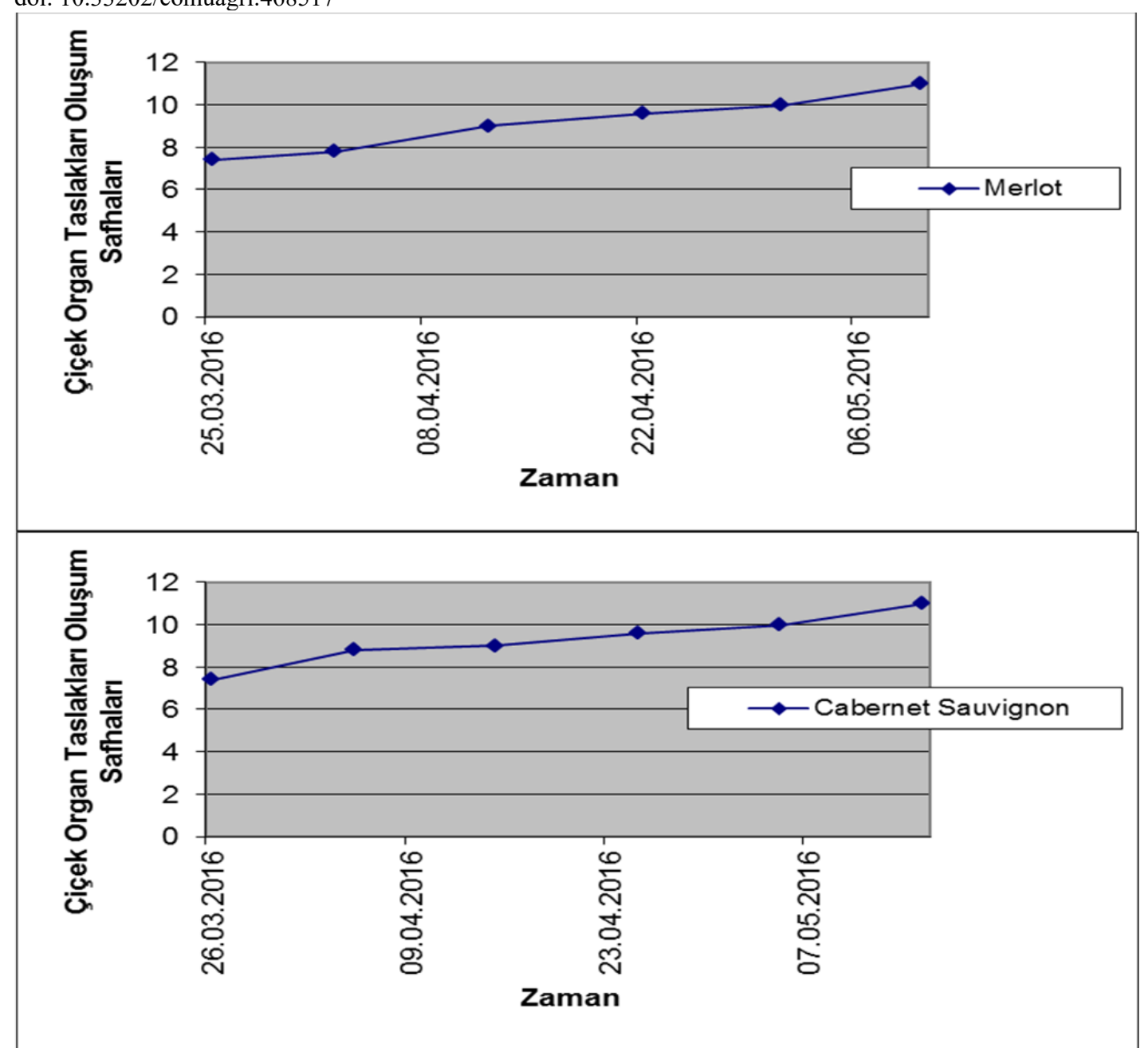

Şekil 11. 'Merlot' ve 'Cabernet Sauvignon' (Vitis vinifera L.) üzüm çeşitlerinin çiçek ve çiçek organ taslaklarının farklılaşma safhaları (Srinivasan ve Mullins 1981'e göre) ve zamanları.

Sonuç olarak bu çalışma bölgemiz koşullarında iki önemli şaraplık çeşitte (Merlot ve Cabernet Sauvignon) kış dinlenme dönemi içerisinde gözlerde generatif organ taslaklarının yapılanmasına yönelik bir gelişme olmadığını, çiçek ve çiçek organ taslaklarının sürme sonrasında farklılaştığını ve gelişmelerinin sepal, petal, erkek organlar ve dişi organ sırasını takip ederek genel olarak üç hafta içerisinde tamamlandığını göstermiştir.

\section{Teșekkür} desteklenmiştir.

Bu proje ÇOMÜ Bilimsel Araştırma Projeleri Komisyonu Başkanlığı tarafından FBA-2015-494 Nolu proje ile

\section{Kaynaklar}

Ağaoğlu, Y.S., 1969. Şaraplık üzüm çeşitlerinde Hasandede, Kalecik karası, Papaz karası, Öküzgözü ve Furmint'in tomurcuk yapıları, floral gelişme devrelerinin tetkiki ve bu çeşitlere uygun budama metotlarının tespiti üzerinde mukayeseli araştırmalar. Ank. Üniv. Doktora Tezi (Basılmamış). Ankara.

Ağaoğlu, Y.S., 1971. A study on the differentiation and the development of floral parts in grapes (Vitis vinifera L. var.). Vitis. 10:20-26.

Alleweldt, B., 1966. Die Differenzierung der Blütenorgane der Rebe.Wein-Wiss. 21:393-402.

Alleweldt, G., Balkema, G.H., 1965. Über die Anlage von Inflorescenz- und Blütenprimordien in den WinterKnospen der Rebe. Z. Acker- Pflanzenbau. 123:59-74.

Alleweldt, G., Ilter, E., 1969. Untersuchungen über die Beziehungen zwischen Blütenbildung und Triebwachstum bei Reben. Vitis. 8:286-313.

Barnard, C., Thomas, J.C., 1933. Fruit bud studies II. The Sultana: Differentiation and development of the fruit buds. J. Counc. Sci. Ind. Res. Aust. 6:285-294 
Boss, P.K., Buckeridge, E.J., Poole, A., Thomas, M.R., 2003. New insights into grapevine flowering. Funct. Plant Biol. 30:593-606.

Breviglieri, N., 1956. Ricerce sulla differnziazione delle gemme e sulla micro e macrosporogenesis nel Sangiovese, nel Canaiol, nel Trebbiano, e nella Malvasia del Chianti. Vallechi Editore Officine Grafice. Firenze.

Carolus, M., 1970. Recherches sur l'organogenèse et l'évolution morphologique du bourgeon latent de la vigne (Vitis vinifera L. var. Merlot). Doctoral thesis, Université de Bordeaux, France.

Çelik, H., 2006. Üzüm çeşit kataloğu. Sunfidan A.Ş. Mesleki Kitaplar Serisi No:3, 166 sayfa.

Ebadi, A., 1996. Effects of pre-flowering conditions of temperature and light on flower and berry development in model grapevines. Thesis (Ph.D.), University of Adelaide, Dept. of Horticulture, Viticulture and Oenology, Avustralya.

Eichhorn, K.W., Lorenz, H., 1977. Phänologische Entwincklungsstadien der Rebe. Nachrichtenblatt des Deutschen Pflanzenschutzdienstes (Braunschweig). 29:119-120

Fidan, Y., 1966. Sofralık üzüm çeşitlerinden Hafızali, Hamburg Misketi, Çavuş, Balbal ve Razakı'nın tomurcuk yapıları ile mahsuldarlık durumları üzerinde araştırmalar. Tarım Bk. Ziraat İş. Gn. Md.lüğü Yayınları D.112, Güneş Matbaacılık T.A.Ş. 89 s. Ankara.

Jones, J.E., Menary, R.C., Wilson, S.J., 2009. Continued development of $V$. vinifera inflorescence primordia in winter dormant buds. Vitis. 48(3):10310

May, P., 1966. The effect of direction of shoot growth on fruitfulness and yield of Sultana vines. Aust. J. Agric. Res. 17:479-490.

Morrison, J.C., 1991. Bud development in Vitis vinifera L. Bot. Gaz. 152:304315.

Odabaş, F., 1976. Erzincan'da yetiştirilen bazı önemli üzüm çeşitlerinin floral gelişme devrelerinin tetkiki ile gözlerin bulundukları yere göre verimliliğinin saptanması ve bu çeşitlerin döllenme biyolojileri üzerinde araştırmalar. Atatürk Üniv. Ziraat Fak. Yayını No: 219, Erzurum.

Pratt, C., 1971. Reproductive anatomy in cultivated grapes-A review. Am. J. Enol. Vitic. 22:92-109.

Scholefeld, P.B., Ward, R.C., 1975. Scanning electron microscopy of the developmental stages of the Sultana inflorescence. Vitis. 14:14-19.

Snyder, J.C., 1933. Flower bud formation in the Concord grape. Bot. Gaz. 94:771-779.

Srinivasan, C., Mullins, M.G., 1981. Physiology of flowering in the grapevine-A review. Am. J. Enol. Vitic. 32: 47-63.

Staudt, G., 1982. Pollen germination and pollen tube growth in vivo and the dependence on temperature. Vitis 21:205-216.

Winkler, A.J., Shemsettin, E.M., 1937. Fruit bud and flower formation in the Sultanina grape. Hilgardia, 10 : 589-611. 